\title{
Acute generalized exanthematous pustulosis induced by hydroxychloroquine: a case with atypical clinical presentation ${ }^{*}$
}

\author{
Hatice Duman ${ }^{1}$ \\ Emek Kocaturk ${ }^{1}$ \\ Ilknur Mansuroglu
}

\author{
Ilteris Oguz Topal ${ }^{1}$ \\ Kubra Cure ${ }^{1}$
}

DOI: http:/ / dx.doi.org/10.1590/abd1806-4841.20175561

\begin{abstract}
Acute generalized exanthematous pustulosis is a rare drug-induced eruption that is characterized by acute, nonfollicular sterile pustules on an erythematous and edematous base. The most frequently implicated drugs are beta-lactam antibiotics. Hydroxychloroquine has been widely used to treat dermatologic and rheumatologic diseases and has been reported as a rare cause of acute generalized exanthematous pustulosis. A 42-year-old female presented with pustular lesions on the skin surface with erythema, facial edema, and occasional atypical target-like lesions after 21 days of treatment with 200mg/ day hydroxychloroquine for rheumatoid arthritis, diagnosed one month previously. We report a case with acute generalized exanthematous pustulosis induced by hydroxychloroquine and treated with dapsone and systemic corticosteroid.
\end{abstract}

Keywords: Acute generalized exanthematous pustulosis; Hydroxychloroquine; Erythema multiforme

\section{INTRODUCTION}

Acute generalized exanthematous pustulosis (AGEP) is a rare and severe cutaneous adverse reaction. Drugs (aminopenicillins, macrolides, sulfonamides) are the most frequently implicated in the etiology. ${ }^{1}$ Hydroxychloroquine (HCQ) has been widely used in the treatment of dermatologic and rheumatologic diseases due to its immunosuppressive and anti-inflammatory properties, and has been reported as a rare cause of AGEP., We report herein a case of HCQ-induced AGEP with atypical clinical presentation.

\section{CASE REPORT}

A 42-year-old female patient was diagnosed with rheumatoid arthritis one month previously and underwent $200 \mathrm{mg}$ /day HCQ and 10mg/day prednisolone treatment. Twenty-one days later, she developed an itchy red rash that began on the front of the trunk and spread to the face and entire body. The patient had no personal or family history of psoriasis.

Clinical examination revealed papules and plaques with erythema on the face and nearly the entire body, and edema of the face. The patient then developed non-follicular pustules on an erythematous base on the entire body; later, atypical target-like lesions appeared on the lower and upper extremities; there was no mucosal involvement (Figures 1 and 2). The patient had high fever $\left(38.2^{\circ} \mathrm{C}\right)$, neutrophilic leukocytosis (WBC count: $15.18 \times 10^{3} / \mathrm{uL}$, neutrophils: $81.8 \%$ ), and in- creased erythrocyte sedimentation rate $(34 \mathrm{~mm} / \mathrm{h})$. Kidney and liver functions were normal. Anti-cyclic citrullinated peptide was increased, and rheumatoid factor, antinuclear antibody, anti-SSA, anti-SSB, and anti-dsDNA were negative. Viral serology for cytomegalovirus, rubella, and toxoplasmosis were unremarkable. A punch biopsy was taken from a pustule on the back. Histopathological examination identified subcorneal pustule formation in the epidermis, acantholytic cells, spongiosis, leukocytes with polymorphic nuclei, and inflammatory infiltrate on the papillary dermis (Figure 3). Based on these findings, the patient was diagnosed with AGEP induced by HCQ. HCQ and prednisolone were withdrawn. The patient was started on intravenous methylprednisolone $60 \mathrm{mg} /$ day. While erythema multiforme-like lesions resolved completely in 7 days, pustular lesions continued to develop irregularly. As the patient's lesions failed to resolve completely, dapsone $50 \mathrm{mg}$ / day was added on the $26^{\text {th }}$ day of treatment. Methylprednisolone was tapered from $60 \mathrm{mg}$ to $0 \mathrm{mg} / \mathrm{d}$ in 2 months. Dapsone treatment was tapered from $50 \mathrm{mg}$ to $0 \mathrm{mg} /$ day in 3 months. The patient's lesions resolved completely on the $35^{\text {th }}$ day of treatment, and there were no new lesions formed during the 18 months of follow-up. One month after treatment was stopped, a patch test performed with $20 \%$ hydroxychloroquine was negative.

Received on 08.01.2016

Approved by the Advisory Board and accepted for publication on 23.02.2016

* Work performed at the Department of Dermatology, Okmeydani Training and Research Hospital - Istanbul, Turkey.

Financial support: none.

Conflict of interest: none.

Department of Dermatology, Okmeydani Training and Research Hospital - Istanbul, Turkey.

Department of Pathology, Okmeydani Training and Research Hospital - Istanbul, Turkey.

(C)2017 by Anais Brasileiros de Dermatologia 


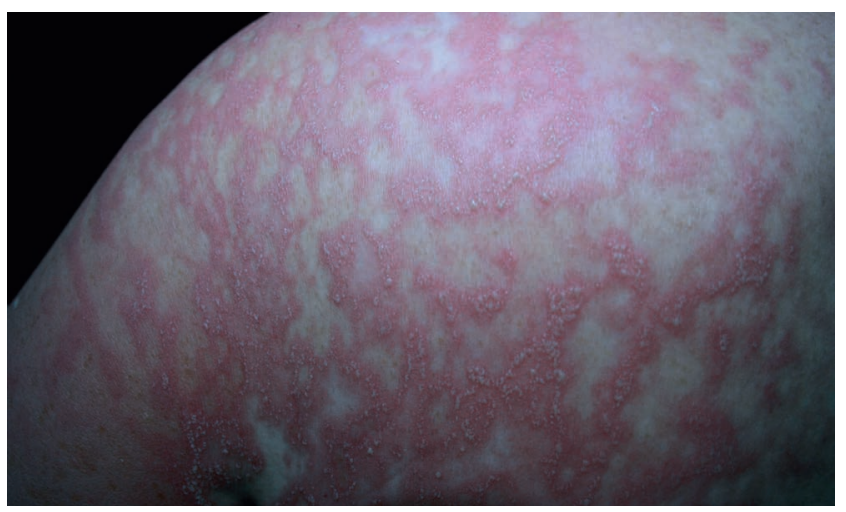

Figure 1: Numerous nonfollicular pustules on the back

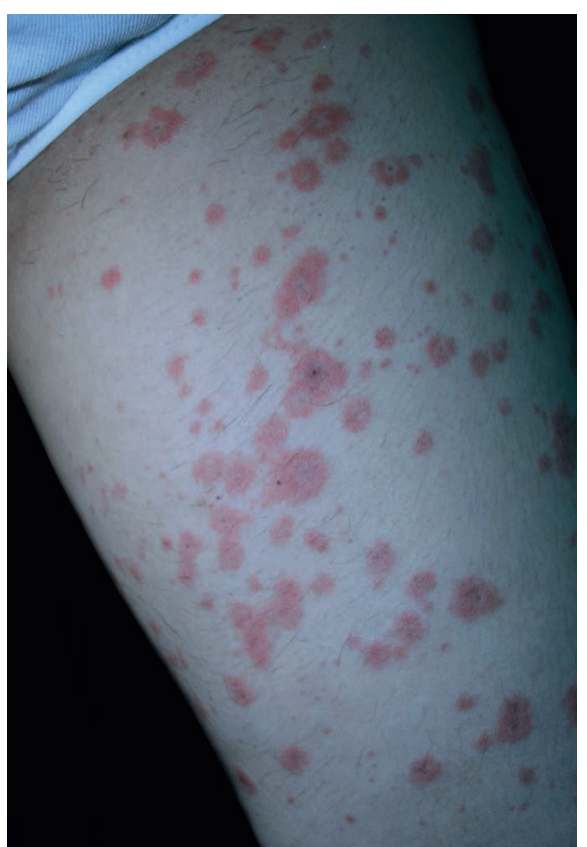

FIgURE 2: Atypical targetoid plaques on the thigh

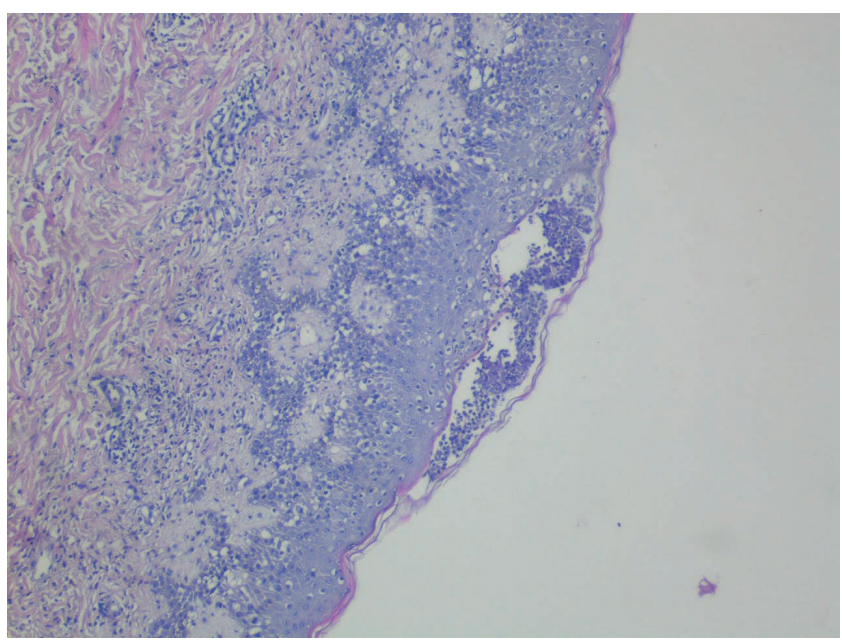

FIGURE 3: Subcorneal pustule, spongiosis, leukocytes with polymorphic nuclei, and inflammatory infiltrate on the papillary dermis (Hematoxylin \& eosin x 40)

\section{DISCUSSION}

AGEP is characterized by sudden onset of an eruption of numerous, small $(<5 \mathrm{~mm})$, non-follicular pustules, high fever $\left(>38^{\circ} \mathrm{C}\right)$, neutrophilia, and acute evolution with spontaneous resolution in less than 15 days. Other rare skin signs are edema of the face, purpura, atypical target-like lesions, and vesicles. ${ }^{1}$

AGEP generally develops as a result of type IVd reactions, and CXCL8 and granulocyte-macrophage colony-stimulating factor (GM-CSF) producing T cells recruit neutrophilic leucocytes via CXCL8 and prevent their apoptosis via GM-CSF release. Bullous drug reactions such as toxic epidermal necrolysis (TEN) develop as a result of type IVc reactions. However, in most cases different type IV reactions may occur together. ${ }^{4}$ Our case had non-follicular pustular lesions on erythematous skin together with atypical target-like lesions. Lateef et al. reported a case like ours that presented with features of AGEP and later developed erythema multiforme-like lesions and was diagnosed as AGEP-TEN overlap as an adverse reaction to HCQ treatment. ${ }^{5}$

AGEP should be differentiated from a wide spectrum of skin diseases that progress with pustular eruption, such as bacterial folliculitis, acne, localized pustular contact dermatitis, Sweet syndrome, impetigo, pemphigus foliaceus, staphylococcal scalded skin syndrome, subcorneal pustular dermatosis, and generalized pustular psoriasis (GPP). ${ }^{1}$ Although differentiation of AGEP from GPP may be difficult, it can be differentiated by histopathological analysis and some clinical features. While widespread edema on the papillary dermis, vasculitis, perivascular eosinophil infiltration, and/or focal keratinocyte necrosis favor AGEP, regular acanthosis and papillomatosis support the diagnosis of pustular psoriasis. The clinical recurrence of similar rash and longer periods of lesions and high fever should suggest GPP. ${ }^{1,6}$ Subcorneal pustular dermatosis progresses with subacute development of larger pustules, often arranged in a circinate pattern. ${ }^{1}$ Nevertheless, the long duration of the condition in our case made the differentiation difficult. Histopathological features in our case were consistent with AGEP, and there was no recurrence after remission.

Antibiotics are the most common causes of AGEP. Other rare causes are non-antibiotic drugs, infections, contact dermatitis, and mercury hypersensitivity. ${ }^{1,2}$ Few cases of AGEP developing on the $21^{\text {st }}$ day of HCQ treatment have been reported recently., ${ }^{2,3,5,7-9}$ Lesions in our case also began on the $21^{\text {st }}$ day of HCQ treatment. According to the EuroSCAR study, which included 100 million people from six countries, 97 cases of AGEP were reported in 4 years; only 7 of these were induced by HCQ, and HCQ was reported to be in the high-risk drug group. ${ }^{10}$ We did not find any other cases of AGEP induced by HCQ in Turkey.

AGEP is usually a self-limiting disease with good prognosis. The condition generally resolves in 15 days after the causative drug is withdrawn. ${ }^{2,3}$ However, our case did not show rapid remission. While pustular lesions continued to develop despite systemic methylprednisolone treatment, dapsone was added. Lesions resolved completely in one month following dapsone and methylprednisolone treatment. We did not find any other cases of AGEP treated with dapsone. In the case reported by Lateef et al., the patient responded well to intravenous hydrocortisone and intravenous immunoglobulin. ${ }^{5}$ We believe 
that typical AGEP lesions accompanied by erythema multiforme-like lesions may cause the disease to progress more intensely.

It should be noted that cases with AGEP not only present with non-follicular pustular lesions but also with atypical target-like lesions, and this should not interfere with the diagnosis. In cases with target-like lesions, it should be noted that the condition could be treatment-resistant and dapsone could be used as an alternative treatment.

\section{REFERENCES}

1. Sidoroff A, Halevy S, Bavinck JN, Vaillant L, Roujeau JC.. Acute generalized exanthematous pustulosis (AGEP)-a clinical reaction pattern. J Cutan Pathol. 2001;28:113-9

2. Paradisi A, Bugatti L, Sisto T, Filosa G, Amerio PL, Capizzi R. Acute generalized exanthematous pustulosis induced by hydroxychloroquine: three cases and a review of the literature. Clin Ther. 2008;30:930-40.

3. Bailey K, McKee D, Wismer J, Shear N. Acute generalized exanthematous pustulosis induced by hydroxychloroquine: first case report in Canada and review of the literature. J Cutan Med Surg. 2013:17:414-8.

4. Posadas SJ, Pichler WJ. Delayed drug hypersensitivity reactions - new concepts. Clin Exp Allergy. 2007;37:989-99.

5. Lateef A, Tan KB, Lau TC. Acute generalized exanthematous pustulosis and toxic epidermal necrolysis induced by hydroxychloroquine. Clin Rheumatol. 2009;28:1449-52.

6. Auer-Grumbach P, Pfaffenthaler E, Soyer HP. Pustulosis acuta generalisata is a post-streptococcal disease and is distinct from acute generalized exanthematous pustulosis. Br J Dermatol. 1995;133:135-9.

7. Park JJ, Yun SJ, Lee JB, Kim SJ, Won YH, Lee SC. A case of hydroxychloroquine induced acute generalized exanthematous pustulosis confirmed by accidental oral provocation. Ann Dermatol. 2010;22:102-5.

8. Evans CC, Bergstresser PR. Acute generalized exanthematous pustulosis precipitated by hydroxychloroquine. J Am Acad Dermatol. 2004;50:650-1.

9. Assier-Bonnet H, Saada V, Bernier M, Clerici T, Saïag P. Acute generalized exanthematous pustulosis induced by hydroxychloroquine. Dermatology. 1996;193:70-1.

10. Sidoroff A, Dunant A, Viboud C, Halevy S, Bavinck JN, Naldi L, et al. Risk factors for acute generalized exanthematous pustulosis (AGEP): results of a multinational case-control study (EuroSCAR). Br J Dermatol. 2007;157:989-96.
MAILING ADDRESS:

Hatice Duman

Okmeydanı Eğitim ve

Araştırma Hastanesi, Deri ve

Zührevi Hastalıklar Kliniği,

Darülaceze Caddesi,

Şişli, Istanbul, Türkiye

E-mail: hatice-ergun15@hotmail.com

How to cite this article: Duman H, Topal IO, Kocaturk E, Cure K, Mansuroglu I. Acute generalized exanthematous pustulosis induced by hydroxychloroquine: a case with atypical clinical presentation. An Bras Dermatol. 2017;92(3):404-6. 